\title{
Editorials
}

\section{The New Millennium: time for a change!}

The turn of the millennium deserves to be celebrated. That is why we decided some time ago to make January 2000 a special millennium issue. The approach of the new millennium inevitably leads to reminiscence. We therefore decided to indulge both in reflection on the rich history of $\mathcal{F C P}$ and in simultaneous speculation on the future. With the help of many people, we have filled this issue with some reflections by our editors on papers from the first issue of $\mathcal{F C P}$ in $1947,{ }^{1-5}$ together with some visionary papers on developments in pathology. ${ }^{6-22}$ We are indebted to all those who have contributed to this issue and extend our thanks to them.

\section{Board membership of $J C P$}

The strength of $\mathcal{F C P}$ has always been its multidisciplinary base. To facilitate this ongoing role we are appointing new members of the board to represent those specialties that are currently underrepresented-that is, chemical pathology, haematology, microbiology, immunology, and statistics. In line with this policy, we have also increased the trainee representation of the board to include one person from each discipline. We hope that this will provide new thoughts and ideas, to meet the requirements of trainee pathologists and new consultants as well as those established in their field.

\section{Journal developments}

We would also like to take this opportunity to highlight changes in the journal which have occurred during the last two years and to announce some which are imminent. We have reduced the turn around time of submissions to $\mathcal{F C P}$ and with the help of our many reviewers, now give authors the initial comment on their paper within an average of five weeks after receipt. Furthermore as a result of the fully electronic in house publishing process, papers are usually published within a three month period after acceptance.

\section{CPD and pathology interactive}

In June this year, $\mathcal{F} C P$ launched its educational CD-ROM, Pathology Interactive. ${ }^{23}$ Financed by the ACP, Pathology Interactive is available as a membership benefit to ACP members and by subscription to non-members. Selected review papers and leaders published in $\mathcal{F C P}$ are accompanied by CPD questions generated or moderated by specialty CPD panels. The CPD questions are presented in Pathology Interactive with related literature and as multiple choice questions. There is an automated self testing program, with scoring and analysis of MCQ scores achieved. Completed tests may be saved as portfolio evidence of learning.

In the year 2000, Pathology Interactive will appear quarterly, with 24 papers and further CPD material. The broadening of the Royal College of Pathologists' view of CPD means that, in the millennium, the range of educational facilities provided by Pathology Interactive will be extended. Instructive case histories, with appropriate questions and model answers, and picture quizzes will provide further access to self learning, while appropriate use of the user notes facility may provide evidence of the reflective process.
Recent discussions with Clair du Boulay, Director of CPD at The Royal College of Pathologists, have resulted in agreement that a range of credits, between 1 and 3, may be awarded for participation in this CPD activity. The actual number of credits to be claimed should be assessed by the individual on the basis of effort expended and learning derived from the activity. This is a self accreditation process, awarded in the following way: one credit should be claimed by participants who read the review article and complete the associated questions; two credits can be claimed if additional reading is done and references followed up; three credits can be claimed if these studies are supplemented by note taking and by identifying learning outcome or further learning needs.

It is felt that this should provide a readily accessible and enjoyable means of CPD activity for all pathologists.

\section{Historical notes}

Beginning with this millennium issue, $\mathcal{F C P}$ will start to publish short historical notes as page fillers, on a regular basis (see p 26, this issue). We hope that these will provide an interesting short read. The historical fillers have initially been commissioned, but we very much welcome your submissions for this type of brief article.

\section{Open peer review}

Peer review has had a crucial role in publishing in medical journals since the 18 th century. ${ }^{24}$ Since then it has developed somewhat haphazardly, with individual journals producing their own versions, basically dependent on the editor in charge at the time.

During the last 15 years, rational inquiries into the workings of editorial peer review have been undertaken. They began with the publication in 1985 of Stephen Lock's seminal work on peer review, a book entitled $A$ Difficult Balance, ${ }^{25}$ and the decision by JAMA that year to hold a conference to present research, as opposed to opinion, on editorial peer review. Three conferences in this field have now been held and have stimulated research into an area which greatly lacked factual support.

Open review, where the names of the reviewers are known to the authors, first appeared in the journal Cardiovascular Research in $1994 .{ }^{26}$ The article fuelled a response from a number of independent critics including Stephen Lock and Richard Smith, past and present editors of the $B M \mathcal{A}$, and Drummond Rennie of $\mathcal{F} A M A$. These editors all argued that there was no ethical justification for the anonymous system of peer review, as knowledge that their names will be disclosed to authors and the public cannot fail to make reviewers more responsible in their comments. ${ }^{27} \mathrm{~A}$ publication in $\mathcal{F} A M A$ in 1998 showed that blinding reviewers to the identity of authors or revealing the identity of reviewers made no editorially significant difference to review quality or review considerations. ${ }^{28}$ Certainly in revealing what makes a good publication for a journal, Black et al showed that high quality review ratings were significantly associated with training in epidemiology or 
statistics, that younger age was an independent predictor of editor's quality assessment, and that review quality increased with time spent up to three hours, but not beyond. ${ }^{29}$

After much debate at the 1999 editorial board meeting of $\mathcal{F C P}$, we decided that an open review process would be more honest, would give credit to reviewers, and would encourage them to be both polite and constructive in their comments. An argument against it would be the reluctance of junior reviewers to criticise the work of senior researchers for fear of damage to their careers. In short, arguments in favour of an open review process are largely ethical. Several journals, including the $B M \mathcal{F}$, have opened the review process and we have decided to follow this practice. From now on, reviewers for $\mathcal{F C P}$ will be invited to reveal their identity, but we will respect their right to remain anonymous if they so wish. In order to protect our reviewers, however, we will make it clear that the decision to accept a paper or not is an editorial one, so that any authors disagreeing with a decision must address their comments to the editors of the journal. A similar decision to open the peer review process was taken separately by the editorial board of Molecular Pathology.

\section{New copyright procedure}

It has long been customary that the authors' only reward for publishing a paper is exposure and "findability"; there has been no direct payment. ${ }^{30}$ Publishers for their part have borne the costs of peer review and of providing the exposure. In return they have taken the rights to their authors' work and the revenues of publishing, and have made money from allowing third parties to reprint articles or translate and distribute them. Recently some authors have become resentful of the fact that publishers take their rights, don't always exploit them well, and then insist on requests for permission when authors want to use their own material. Along with other journals in the BMJ Publishing Group, the Fournal of Clinical Pathology and its Molecular Pathology edition have traditionally asked authors to assign their copyright to the publisher to exploit those rights, and tackle infringements without having to go back to the author each time. In practice the publisher has, however, always allowed authors to use their material in other publications, and for their own teaching and research purposes without charge. From now on the fournal of Clinical Pathology and Molecular Pathology will change this traditional policy. Authors will no longer be asked to assign their copyright to the publisher. Instead, we will ask for an exclusive licence. In practice this gives the journal almost the same control as before, but authors will no longer have to ask for permission to use their material for any non-commercial use. In addition, we will give one nominated author, research group, or institution $10 \%$ of the revenue we make from a commercial reprint order (over $£ 1000$ ) for their paper.

We hope that you will appreciate the changes to the $\mathcal{F C P}$ and that you will enjoy this special issue. We wish you all the best for the new millennium.

HELEN HOLZEL PAUL J VAN DIEST

1 Holzel H. Microbiology. $\mathcal{F}$ Clin Pathol 2000;53:3-4

2 van Diest PJ. "On familial intestinal polyposis" by C E Dukes. 7 Clin Pathol 2000;53:4-5.

3 Crook M. Chemical pathology: what has changed? f Clin Pathol 2000;53:6.

4 Spickett G. Giant cell arteritis at the millennium. F Clin Pathol 2000;53:5-6.

5 Reid MM. Haematology. 7 Clin Pathol 2000;53:4.

Bartels PH. Future directions in quantitative pathology: digital knowledge in diagnostic pathology $\mathcal{F}$ Clin Pathol 2000;53:31-7.

Fox H. Is H\&E morphology coming to an end? F Clin Pathol 2000;53:38-40.

7 Fox H. Is H\&E morphology coming to an end? F Clin Pathol 2000;53:38-40. Jones AM, Gaspar HB. Immunogenetics:
deficiency. $₹$ Clin Pathol 2000;53:60-5.

N Kirkham. The pathologist in the 21 st century: generalist or specialist? $\mathcal{F}$ Clin Pathol 2000;53:7-9.

10 Wade A. Fear or favour? Statistics in pathology. F Clin Pathol 2000;53:16-18.

11 Bosman FT. Continuous professional development in pathology: a continental view. F Clin Pathol 2000;53:10-12.

12 Boxer M. Molecular techniques: divide or share? f Clin Pathol 2000;53:19-

21.
Crocker J. The future of scientific communication in pathology. 7 Clin Pathol 2000;53:13-15.

14 Crook MA. Near patient testing and pathology in the new millennium. $\mathcal{F}$ Clin Pathol 2000;53:27-30.

15 Lowdell MW, Koh MBC. Immunotherapy of AML: future directions. $7 \mathrm{Clin}$ Pathol 2000;53:49-54.

16 Goddard MJ, Foweraker JE, Wallwork J. Xenotransplantation-2000. f Clin Pathol 2000;53:44-8.

17 Eden OB. Therapeutic trials in childhood ALL: what's their future? $\mathcal{F}$ Clin Pathol 2000;53:55-9.

18 Swaminathan R, Wheeler M. Robotics into the millennium. $\mathcal{F}$ Clin Pathol 2000;53:22-6.

19 Pitt TL, Saunders NA. Molecular bacteriology: a diagnostic tool for the millennium. 7 Clin Pathol 2000;53:71-5.

20 Meijer CJLM, Walboomers JMM. Cervical cytology after 2000, where to go? f Clin Pathol 2000;53:41-3.

21 Cookson BD. Infection and antimicrobial prescribing control in the new millennium: nightmare or nirvana? f Clin Pathol 2000;53:66-70.

22 Preiser W, Elzinger B, Brink NS. Quantitative molecular virology in patient management. F Clin Pathol 2000;53:76-83.

23 Holzel H, Diest PJ van, Heard S. Continuing professional development: is the future Pathology Interactive? $\mathcal{F}$ Clin Pathol 1999;52:401-2.

24 Kronick DA. Peer review in the 18 th-century scientific journalism. $7 A M A$ 1990;263:1321-2.

25 Lock S. A difficult balance: editorial peer review in medicine. London: Nuffield Provincial Hospitals Trust, 1985.

26 Fabiato A. Anonymity of reviewers. Cardiovasc Res 1994;28:1134-9.

27 Rennie D. Editorial peer review: its development and rationale. In: Godlee F, Jefferson T, eds. Peer review in health sciences. London: BMJ Publishing Group, 1999:3-13.

28 Rooyen $\mathrm{S}$ van, Godlee F, Evans S, et al. Effect of blinding and unmasking on the quality of peer review. $F A M A 1998 ; 280: 234-7$.

29 Black N, Rooyen S van, Godlee F, et al. What makes a good reviewer and a good review for a general medical journal? $\mathcal{F A M A} 1998 ; 280: 231-3$.

30 Kennard CJ. Giving something back to the authors. $\mathcal{F}$ Neurol Neurosurg Psychiatry 1999;67:419-27.

\section{Millennium Festival of Medicine}

This special issue of $\mathcal{F C P}$ is a part of the Millennium Festival of Medicine - a programme of diverse events and activities for healthcare professionals and the wider public running throughout the year in the United Kingdom to celebrate the turn of the century and mark the advances and challenges in medicine. At the heart of the celebrations is the Festival Keynote Conference (6-10 November 2000, London). Parallel sessions which may be of interest to readers of JCP are: Testing and treating healthy people (6 November) Molecular biology and medicine (8 November) Emerging infections, diseases and international health problems (10 November).

Further information on the programme of events and activities is available at www.medicine2000.org or by contacting tel +44(0)171383 6872; fax +44(0)171383 6220; email: medicine2000@medicine2000=org. 


\section{Reflections on the first issue of $\mathcal{F C P}$}

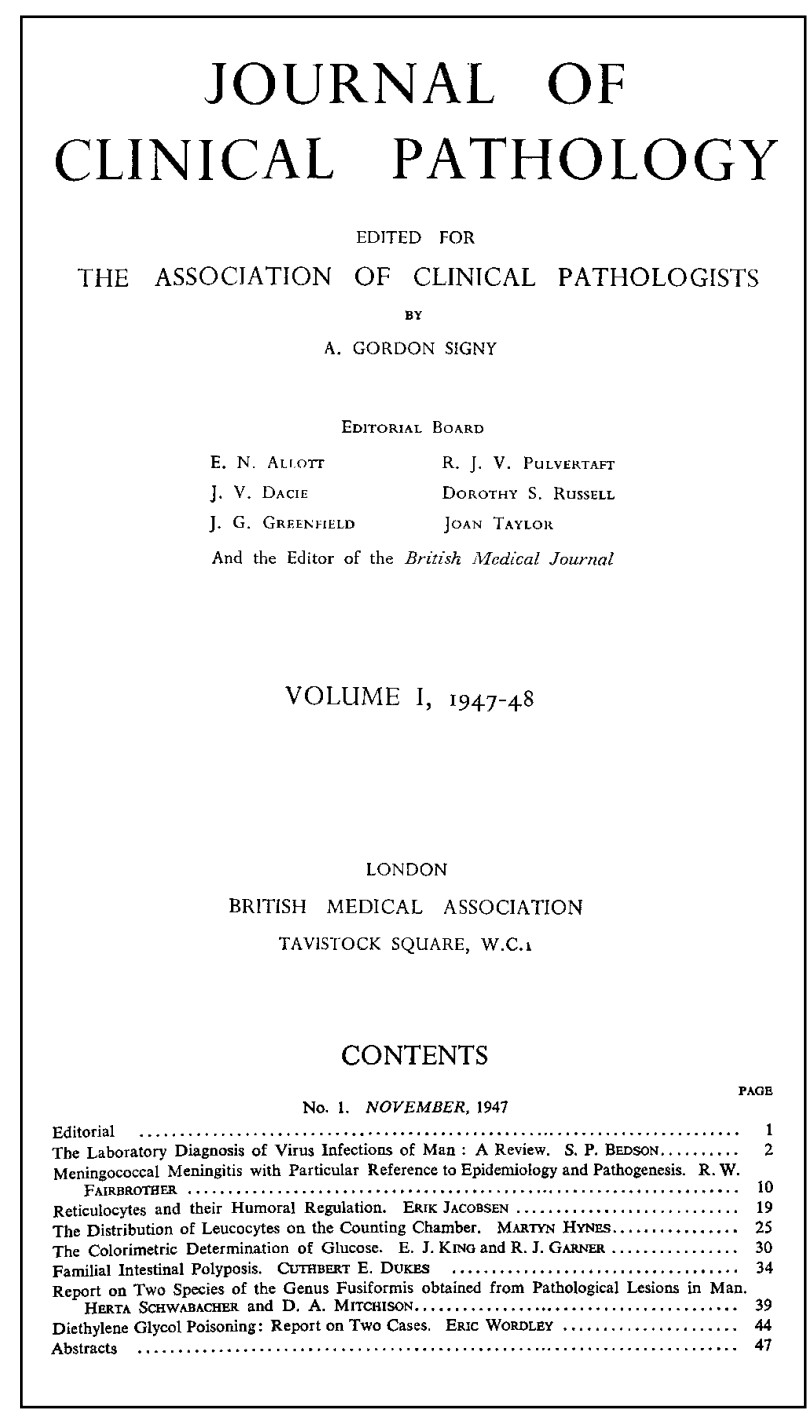

\section{Microbiology}

Leading the way as the first article in the first issue of $\mathcal{F C P}$ in 1947 , Bedson wrote a magnificent review of the laboratory diagnosis of virus infections of man. ${ }^{1}$ He showed a formidable understanding of the then current situation, stating that it was still impossible to say whether viruses were living microorganisms or not. He highlighted the doubt that all the agents grouped together as viruses were "of the same nature." How right he was. The major group of agents he discussed were the so called large viruses. His descriptions of the clinical picture and means of investigating the "viral causes" of trachoma inclusion conjunctivitis, lymphogranuloma venereum, and psittacosis were so well observed that they remain true today.

Bedson discussed the different means of viral diagnosis available in 1947. He described the use of specific histological change, virus isolation by use of eggs or animal inoculation, for example the use of monkeys as the only available means of detecting poliovirus. Serological investi- gations included use of precipitins, agglutination, complement fixation, and the new haemagglutination inhibition test for influenza. He discussed how complement fixation could be used for the detection of variola antigen in the vesicles and crusts of skin lesions and the novel use of red cell agglutination for virus detection. In his final remarks, Bedson emphasised the important part which the laboratory can play "not just occasionally by making special investigations but in an everyday routine way."

Taking the role of microscopy further, Madeley in the Origins series in $1997^{2}$ described the history of electron microscopy (EM) from its origin in Germany in 1934 to its development as a valuable diagnostic tool. The first pictures of viruses, those of plant viruses such as tobacco mosaic virus, were published in 1941. During the following 10 years micrographs of one virus after another appeared. By the 1960s, the use of the electron microscope had progressed to become an integral part of the diagnosis of smallpox. It was purchased for this reason by a considerable number of diagnostic laboratories. With the elimination of the disease in 1976, however, a new role evolved and EM became used for the diagnosis of viral skin lesions such as warts and molluscum contagiosum. Its importance as a diagnostic tool had receded. By the mid 1970s viruses had been identified as the cause of many diseases. In particular, they were thought to be the major cause of common episodes of diarrhoea and vomiting. Madeley described the progress of the recognition of EM as a tool for the diagnosing of viral causes of diarrhoea common in children, both here and in the tropics. By way of Kapikian's use of EM in finding Norwalk agent as the cause of an outbreak of diarrhoea in Ohio in 1972, Madeley led us through Bishop's findings of rotavirus in thin section EM of biopsies from children with possible malabsorption, to the work of Flewett. In 1973, Flewett showed that rotavirus could be seen by EM directly in stool extracts. In his own work in 1975, Madeley used EM to demonstrate the importance of astroviruses and caliciviruses as causative agents of diarrhoea and vomiting, and in the 1980s Caul and Appleton used EM to highlight the importance of a variety of small round structured viruses.

Madeley wrote of the gradual fall in the use of this expensive piece of equipment in the current climate of cost conscious diagnostic laboratories. He ended by saying that use of EM with a speed of diagnosis some 15 minutes at its best, coupled with its versatility in being able to detect a wide variety of viruses without prior selection, should ensure its continued use.

A diagnosis of viral infection made, but then what? In his article in 1999 on recent advances in antiviral therapy, Kinchington discusses the range of antiviral treatment now available. ${ }^{3}$ Drugs for treating HIV infection are discussed and the explanation of their activity at molecular level makes a complex subject interesting for experts and non-experts alike. The arrival of HIV had changed the perception of the importance of the specialist department of virology. It led to an increased activity in antiviral research into novel treatments for other viruses, including hepatitis $\mathrm{B}$ and $\mathrm{C}$ and the growing herpes virus group. Kinchington expressed the view that future antiviral chemotherapy will be concerned with the search for compounds that can target viral enzymes. He wrote that the identification and cloning of viral genomes is now routine, because of the availability of PCR technology, even when 
no cell system for growing the virus itself exists. Bedson would have been surprised, or would he?

H HOLZEL

Department of Microbiology, Hospital for Sick Children, Great Ormond Street, London WC1, UK

1 Bedson SP. The laboratory diagnosis of virus infections of man; a review. $\mathcal{F}$ Clin Pathol 1947;1:2-9.

2 Madeley CR. Electron microscopy and viral diagnosis. 7 Clin Pathol 1997;50:454-6.

3 Kinchington D. Recent advances in antiviral therapy. F Clin Pathol 1999;52: 89-94.

\section{Haematology}

What happened in the world of haematology in the latter half of the last millennium and how has this been reflected in the pages of $\mathcal{F} C P$ ? A sample, chosen by me, of a few papers published early, somewhat later, and much more recently in the Journal's publishing history will certainly illustrate my enthusiasms, even if they will not answer either question satisfactorily for many haematologists.

In the very early days, Dacie and White ${ }^{1}$ published a review (in those days reviews were often both scholarly and truly elegantly written affairs, and this is such an example) of erythropoiesis and its study by bone marrow biopsy. I know microscope lenses and condensers have improved enormously since then, as has modern colour photography, but the careful observation and descriptive power of conscientious microscopists still shines through. Observation of snapshots of this dynamic organ was really all that was available because bone marrow culture systems, as we know them today, would have been science fiction to haematologists in the $1940 \mathrm{~s}$. It is also fascinating to see the sang froid with which haematologists in those days would contemplate and perform a trephine biopsy on the sternum!

Massive leaps in the technology of cell counting, understanding of clotting, and other areas took place between 1949 and the 1970s. However, although I remain at heart a morphologist, it is the more "basic biology" advances (especially as they affect malignant haematology) that have really gripped my imagination. In 1975 Habeshaw and Stuart ${ }^{2}$ reported on cell receptor studies in histiocytic lymphoma, still called reticulum cell sarcoma in those days. Their paper illustrated the way early techniques of sheep red cell rosetting and fluorescence microscopy with polyclonal antibodies could be used to determine $\mathrm{T}, \mathrm{B}$, or null phenotypes from single cell suspensions of these lymphomas. Of course such techniques had already been used for a few years by pure immunologists and early classifications, of childhood leukaemia in particular, were already being compiled. The dawn of the true expansion of immunological diagnosis is reflected, six years later, in the review by Hoffbrand and Janossy. ${ }^{3}$ Not only had the common acute lymphoblastic leukaemia antigen been discovered by Greaves, but Ritz had produced a monoclonal antibody to it, one among an expanding battery of monoclonal antibodies to $\mathrm{T}, \mathrm{B}$, and myeloid cells to come out of numerous laboratories round the world. The speed with which such reagents entered routine diagnosis was extraordinary. The size of antibody panels soon demanded flow cytometry, both for the improved accuracy that came from analysing large numbers of fluorescing cells and in order that fluorescence microscopists were not submerged by the deluge.

The last 10 years have witnessed a similarly breathtaking explosion in what was once called "the new genetics." DiGiusseppe and Kastan ${ }^{4}$ provided, in 1997, a review of apoptosis in haematological malignancies which explored current knowledge of the action of a number of genes such as bc1-2, p53, Fas, and perhaps the most extensively and longest studied genetic rearrangement, the fusion gene $\mathrm{BCR} / \mathrm{ABL}$ - and of the effects they might have on programmed cell death and resistance to chemotherapy. Molecular biological knowledge is now expanding faster than haematologists can assimilate it; we can barely begin to frame the important questions about how best to exploit this knowledge, let alone answer those questions. My feeling is that over the next 20 years we shall discover just how difficult it really is to harness these discoveries and decide which are truly important to our every day management of haematological malignancy. In the meantime it's a field day for the basic scientists!

M M REID

Department of Haematology, The Royal Victoria Infirmary, Queen Victoria Road, Newcastle upon Tyne, UK

1 Dacie JV, White JC. Erythropoiesis with particular reference to its study by biopsy of human bone marrow: a review. f Clin Pathol 1949;2:1-32.

2 Habeshaw JA, Stuart AK. Cell receptor studies on seven cases of diffuse histiocytic malignant lymphoma (reticulum cell sarcoma). F Clin Pathol 1975; 28:289-97.

3 Hoffbrand AV, Janossy G. Enzyme and membrane markers in leukaemia: recent developments. F Clin Pathol 1981;3:254-62.

4 DiGiusseppe JA, Kastan MB. Apoptosis in haematological malignancies. $\mathcal{F}$ Clin Pathol 1997;50:361-4.

\section{On "Familial intestinal polyposis" by C E Dukes}

All papers from the first issue are well before my time, but I had no problem making my choice. Going through the index, my eye was immediately caught by a name (Dukes), and seeing the title of the paper (Familial intestinal polyposis) I realised this had to be my pick. With today's knowledge, it was fun to look back and see what at that time was already known and what may have been wrong or incomplete.

Well, nothing much was wrong. The paper ${ }^{1}$ gives an accurate description of the first data on families with polyposis and colorectal cancer. It is explained that in some families multiple polyps occur, strictly confined to the colon, and that this predisposes to colonic cancer. Several statements still hold true: the young age at diagnosis of cancer, the "tendency for malignant disease to begin at an earlier age period in each succeeding generation," the need for "constant medical supervision," and that "no other method of treatment than surgery has any permanent effect on the course of the disease." However, the mentioned "waiting game," where "a radical excision may be undertaken as soon as malignancy is detected," has been replaced by preventive colectomy at a certain age, which was at that time apparently not an option. Interestingly, although the relation between the polyps and subsequent cancer is made clear, it is never explicitly stated that the cancers in fact usually occur in the polyp.

Several statements are vague or incomplete in the light of today's knowledge, such as those on the pattern of inheritance. It is stated that both males and females are affected, that transmission can be by the female or the male, and that about half the family members are affected, pointing to an autosomal dominant pattern. In this respect, the remark that "polyposis may possibly result from the chance mating of two individuals, each of whom was destined to die of cancer of the intestine" sounds somewhat weird. The observation that in two of 10 St Mark's Hospital families studied the disease seemed to start with both father and mother, who died of cancer of the rectum or colon, can 
probably be explained by the chance mating of two carriers, leading to an excessive number of affected individuals in this family.

Although all the patients described in the paper are considered to have the same syndrome, knowledge has progressed and we now discern several syndromes. From the description of the patients' histories, it seems that most of them had a disease which we would now designate familial adenomatous polyposis (FAP). However, the four very young patients would now be considered to have juvenile polyposis, and the patients from the original Warthin paper which was cited by Dukes (cancer family "G") were later, of course, found to have a different disease which we now call hereditary non-polyposis colorectal cancer (HNPCC) syndrome, based on a germline mutation in one of the genes coding for the DNA mismatch repair apparatus. $^{2}$

It is stated that "members of polyposis families show no special proclivity to the development of tumours in any other organ of the body than the intestine," which we now know not to be true. Several phenotypical variants of this inherited disease caused by a germline mutation in the APC gene exist. Gardner's syndrome (polyposis, epidermoid cysts, and osteomas), a proportion of the cases with Turcot's syndrome (polyposis and brain tumours), and AFAP (attenuated familial adenomatous polyposis - that is, APC mutations with less than 100 polyps and colorectal cancer at a later age than in "common" FAP) all belong within the spectrum of FAP. In addition, since many FAP patients do not now die from colorectal cancer, other tumours appear, such as duodenal polyps, desmoid tumours, and thyroid and hepatocellular cancers. HNPCC also involves an inherited predisposition to cancer which is certainly not limited to the large intestine. Endometrial, ovarian, gastric, and urothelial cancers often occur in patients with HNPCC, as well as cancers at other sites. The combination of sebaceous gland tumours and an internal malignancy is known as Muir-Torre syndrome. Based on the presence of microsatellite instability, it has been suggested that a proportion of Muir-Torre syndrome cases would be variants of HNPCC.

Nevertheless, there is no doubt that this review from over 50 years ago is in retrospect a seminal paper, which has to a large extent withstood the course of time. Since it was written, St Mark's Hospital has developed into one of the leading institutes for follow up studies of hereditary and sporadic polyps.

I am grateful to Dr Gerrit Meijer for critically reading the manuscript. PAUL J VAN DIEST

Department of Pathology, Free University Hospital, 1007 MB Amsterdam, The Netherlands

1 Dukes CE. Familial intestinal polyposis. F Clin Pathol 1947;1:34-7. 2 Lynch HT, Krush AJ. Cancer family "G" revisited: 1895-1970. Cancer 1971;27:1505-11.

\section{Giant cell arteritis at the millennium}

It is both interesting and frequently depressing looking back at the historical medical literature: interesting because our predecessors were usually far better observational clinicians than we are today, and depressing because so much of what we believe to be new and exciting today can often be found perfectly described, although maybe not fully understood, 50 years ago. The lack of emphasis on observational and clinical skills and over-reliance on inves- tigations without understanding their limitations is, at a personal level, one of the most worrying developments in medicine. Equally our reliance on computer based literature searching tends to eliminate older papers from the scope of searches, meaning that much useful clinical observation is simply consigned to dusty shelves, never to see the light of day again, or worse just scrapped as of no value.

There is therefore a certain pleasure to reading the excellent review of giant cell arteritis and the accompanying case report by Harrison. ${ }^{12}$ The review seems just as pertinent today as it must have when it first appeared. The clinical features are clearly described and the complications discussed. A most depressing feature is how little the topic has advanced in the time that has elapsed since Harrison put pen to paper. This is confirmed by comparing Harrison's review with one almost 50 years on by Hunder. ${ }^{3}$ Yes, we have plenty of interesting immunohistology, identifying the type of cells involved in the inflammatory process, and we understand links to HLA DR4, but, no, we are no wiser as to the true cause of this enigmatic disease. There is still no simple diagnostic test other than arterial biopsy, and even this test has its problems owing to the patchy nature of the process, a fact that was recorded by Harrison. ${ }^{1}$

The histology is well described and the review of the case reports previously published indicates the inappropriateness of calling this disease "temporal arteritis." This is a disease that affects all major arterial systems, and is certainly a cause of inflammatory aortic aneurysms. Despite the fact that this generalised arterial involvement was well known over 50 years ago, current reports still refer to "temporal arteritis": surely it is time that this nomenclature was dropped. One might argue "what's in a name," but here the misnomer misleads clinicians into thinking that this is a disease of a specific arterial territory, often with disastrous consequences. Hunder ${ }^{3}$ provides an excellent table of the signs and symptoms, and discusses the involvement of arteries other than the temporal arteries, which may be present in $10-15 \%$ of cases.

One area not recognised in Harrison's review is the link with polymyalgia rheumatica, which was described in 1963 by Alestig and Barr. ${ }^{4}$ The precise link between the two conditions is still poorly understood and there is little evidence for a vasculitic basis for polymyalgia.

Harrison's article is of particular interest because of course there was no specific treatment available at the time, so the natural history and underlying complications could be reviewed. The natural history in non-fatal cases seemed to have been that patients would eventually undergo spontaneous recovery after a period of months or years. This suggests that steroids probably do not radically alter the time course of the disease, although they undoubtedly relieve the acute symptoms. Indeed the only treatment identified by Harrison is the curiously therapeutic effect of temporal artery biopsy in relieving symptoms (in 21 cases). The current treatment of steroids with or without second line immunosuppressive agents, although not available in 1948, was introduced in the 1950s, and again we have seen little in the way of changes to the therapeutic approach. Indeed this is a criticism of the approach to many immunological diseases, where we are still reliant on 40 year old treatments, an indicator perhaps of the discrepancy between the huge strides made in basic immunology compared with the rather limited progress in translating this knowledge into clinically useful advances in treatment.

G P SPICKETT

Regional Department of Immunology, Royal Victoria Infirmary, Newcastle upon Tyne, UK 
1 Harrison CV. Giant-cell or temporal arteritis: a review. 7 Clin Pathol 1948;1:197-211.

2 Cohen $\mathrm{H}$, Harrison CV. Temporal arteritis: a report of three cases. $\mathcal{F}$ Clin Pathol 1948;1:212-16.

3 Hunder G. Giant cell arteritis and polymyalgia rheumatica. Med Clin North Am 1997;81:195-219.

4 Alestig K, Barr J. Giant cell arteritis: a biopsy study of polymyalgia rheumatica, including one case of Takayasu's disease. Lancet 1963;i:122830

\section{Chemical pathology: what has changed?}

Is there really anything new under the sun? ${ }^{1}$ I wondered, as I was asked to select a chemical pathology paper from the first volume of the first edition of $\mathcal{F C P}$, to discuss in the millennium issue of the journal. Furthermore, would it be possible for me to find a paper from over 50 years ago that would reflect chemical pathology practice at the time and contrast this with current trends in the field as we lead up to the millennium celebrations? A paper that did stand out was that by E J King and R J Garner, from the British Postgraduate Medical School, entitled "The colorimetric determination of glucose." " This was starkly different from those current papers that one tends to browse through, describing knock out mice, prions, cytokines, retroviruses, genetically modified foodstuffs, or adhesion molecules. It was written in 1947 during the preconception years of the NHS, at a time when laboratory accreditation, the Royal College of Pathology, CME log books, and NEQAS were only twinkles in laboratory medicine's eyes.

The first striking feature of this paper is the mention in the introduction of the difficulty the authors had in obtaining analytic reagent grade quality reagents for the glucose colorimetric assay; they attributed this to the war years. Alas, in this sense perhaps little has changed, for as I write this article British forces attack Serbian positions in the Balkans, a tragic example of a "...small war on the heels of small war." 3 The contamination of their sodium carbonate reagent with sodium bicarbonate resulted in poor colour stability and variable glucose assay results. Today we perhaps take for granted the ease of obtaining high quality reagents off the shelf from large commercial suppliers.

Another feature of this paper is the politically incorrect use of non-SI units. This is almost guaranteed to cause enthusiasts from the pro-SI and anti-SI lobbies to write letters to the Journal to generate debate, although I have to say that $\mathrm{mmol} / 1$ is a lot easier to write than $\mathrm{mg}$ per $100 \mathrm{ml}$ for the units of glucose. Nevertheless, there is still no international agreement on units for reporting clinical chemistry results.

As anyone should know who works in a modern chemical pathology laboratory, fast turnaround times are important for clinicians to ensure optimal patient management. However, I cannot imagine that manually filtering blood, after protein precipitation, followed by 10 minutes of boiling the filtrate with copper reagent, followed by another 10 minutes for assay colour development with Folin-Wu phosphomolybdic acid would inspire an overstretched MLSO to assay many blood samples for glucose. Nor would the beer barrel quantities of sample and reagent attract delight in a multidiscipline combined laboratory working flat out in a shift system; amazingly, the final assay reaction volume exceeded $5 \mathrm{ml}$ ! I would be surprised, also, if the authors of this historic paper would have guessed that 50 years later glucose could be measured within minutes, using microvolumes of sample and reagent by dry chemistry techniques, biosensors, or multianalysers, some of which can also measure at least 20 other analytes.

Furthermore, would they have prophesied that diabetic patients would be monitoring their own blood glucose as part of near patient testing and using these results to adjust their insulin? In addition, could they have believed that in 1995 more than $£ 40$ million would be spent in the United Kingdom on home glucose monitoring alone! ${ }^{4}$

Having read this fascinating, seminal, and historic paper by King and Garner I can only conclude that we have come a long way in laboratory medicine since they published their article. With the exponential growth in scientific and medical knowledge we are likely to have many further surprises in the new millennium. Fifty years is a long time in laboratory medicine and we need to be prepared for the changes if we are to survive under the sun.

M A CROOK

Department of Chemical Pathology, Guy's and St Thomas' Hospital, London SE1, UK

1 Ecclesiastes 1: 9. The Holy Bible, new international version. 2 King EJ, Garner RJ. The determination of glucose. F Clin Pathol 1947;1:303.

3 Robert Lowell. In: Waking early Sunday morning [poetry selection]. London: Faber, 1978 .

4 Crook M, Purcheon A. Near-patient testing and diabetes mellitus. In: Handbook of near-patient testing. London: Greenwich Medical Media, 1999: 77-90. 